\title{
The visual perception of lines on the road
}

\author{
Dennis M. Shaffer ANd ANDrew B. Maynor \\ Ohio State University, Mansfield, Ohio \\ AND \\ WINDY L. RoY \\ Arizona State University West, Phoenix, Arizona
}

\begin{abstract}
The present work demonstrates that observers grossly underestimate the length of lines parallel to their line of sight. In Experiment 1, observers, working from memory, estimated the length of a dashed line on the road to be $0.61 \mathrm{~m}$. This result is consistent with observers' using an average visual angle converted to the physical length of visible lines on the road to estimate their length. In Experiment 2, observers gave verbal and matching estimates that significantly underestimated the length of a $3.05-\mathrm{m}$ line on the ground that was parallel to their line of sight. In Experiment 3, observers significantly underestimated the length of dashed lines on the road while in a moving car. The results of Experiments 1 and 3 are described well by Euclidean geometry, whereas the tangle model that utilizes an increasing function of the visual angle to describe perceived extent best describes the results of Experiment 2.
\end{abstract}

For years, psychophysicists have investigated the relationship between physical extent and observers' visual perception of extent. Although some of this work has focused on the metrics of visual space in general and has shown that visual space is curved (i.e., hyperbolic or elliptical; Battro, Netto, \& Rozestraten, 1976; Blank, 1958; Koenderink, van Doorn, \& Lappin, 2000; Luneburg, 1950), an abundance of other work has focused on how visual space is distorted in an affine manner, so that perceived intervals in depth (or parallel to the observer's line of sight) appear to become systematically compressed with depth, relative to perceived intervals in the horizontal or vertical directions (i.e., the frontoparallel plane perpendicular to the observer's line of sight; Beusmans, 1998; Foley, Ribeiro-Filho, \& Da Silva, 2004; Gilinsky, 1951; Gogel, 1964; Haber, 1985; Harway, 1963; Hecht, van Doorn, \& Koenderink, 1999; Kudoh, 2005; Loomis, Da Silva, Fujita, \& Fukusima, 1992; Loomis \& Philbeck, 1999; Matsushima, de Oliveira, Ribeiro-Filho, \& Da Silva, 2005; Norman, Crabtree, Clayton, \& Norman, 2005; Norman, Todd, Perotti, \& Tittle, 1996; Todd \& Norman, 2003; Todd, Tittle, \& Norman, 1995; Toye, 1986; Wagner, 1985). Some of this work has shown that when extents are viewed in near space, depth intervals must be made approximately $1.5-2$ times as large to be perceived to be the same as horizontal extents (Norman et al., 1996; Todd \& Norman, 2003). Many of these studies have been conducted in outdoor environments with several stakes or L-shapes placed on an outdoor grassy field at different distances. They typically have observers either estimate distances between stakes or adjust a stake or one part of the L-shape so that a depth interval is perceived to be equivalent to a horizontal interval. This work has shown that in cases in which stakes are $\sim-40 \mathrm{~m}$ away from the observer, depth intervals are adjusted to be between 1.5 and 2 times as large, relative to the horizontal interval of the same physical size (Foley et al., 2004; Hecht et al., 1999; Kudoh, 2005; Loomis et al., 1992; Loomis \& Philbeck, 1999; Matsushima et al., 2005; Norman et al., 2005; Toye, 1986; Wagner, 1985). Hecht et al. concluded that many findings from other studies could be rephrased in terms of depth compression and suggested that there is a general mechanism for sagittal compression for far space.

The affine distortion of perceptual space shown in the aforementioned work has been applied mainly to unfilled distances between stakes or with L-shape stakes connected to one another (or touching one another) on the ground. To our knowledge, less work has been done considering whether an object or a filled area, such as a stake placed on the ground plane parallel to the line of sight of the observer, would also be subject to the large affine distortions that distances between stakes are. Previous work has shown that unfilled space is generally seen as much smaller than filled space (Luria, Kinney, \& Weissman, 1967). In addition, would one get the same depth compression for the depth portion of an L-shape if the horizontal portion were removed? That is, how, if at all, do the affine distortions affect perception of an object or filled space on the ground plane parallel to the line of sight of the observer? We sought to explore these questions, using the land line markings, or dashed lines, that separate two or more lanes of traffic on roads. In essence, these are simply filled space on the ground plane, since they are painted on the road. In

D. M. Shaffer, shaffer.247@osu.edu 
the United States, the federal government recommends that these markings be $3.05 \mathrm{~m}(10 \mathrm{ft})$ in all states. States such as Massachusetts and Ohio used to have a standard of 4.57-m (15-ft) lines for all Interstate highways (10-15 years ago), with spaces in between the lines of 7.62-9.15 m (Harte, 1975). In previous work evaluating people's perceptions of lines on the road, observers underestimated their length by about $50 \%$ (Harte, 1975). Presently, states such as Ohio have a recommended standard of 3.05-m lines with a space of $9.15 \mathrm{~m}$ between the lines (Ohio Dept. of Transportation, 2005).

There were three foci of the present work. First, we wanted to evaluate the perceived extent of these lines and to investigate whether the same compression of depth that occurs with distances between stakes and with depth-towidth ratios of stakes on the ground plane would apply to memorial representations of the lines on the road and, in actual viewing conditions, of the lines at different distances and from different perspectives. Second, we investigated whether Euclidean geometry would describe observers' estimates of the extent of the lines well. Finally, since most of the findings cited to this point have provided strong evidence that the relationship between physical and perceived space is non-Euclidean, we also wanted to test whether our results would fit with the tangle model proposed by Foley et al. (2004).

\section{EXPERIMENT 1}

Experiment 1 was designed to examine how long observers, working from memory, would estimate the lines on the road to be. According to the Ohio Department of Transportation in 1994 (when Experiment 1 was conducted), the length of each dashed line that separated two or more lanes of traffic headed in the same direction on Interstate 76 in Ohio was $4.57 \mathrm{~m}$ (or $15 \mathrm{ft}$ ), although presently they are $3.05 \mathrm{~m}$ (or $10 \mathrm{ft}$ ).

\section{Method}

\section{Participants}

Three hundred fifty-five introductory psychology students, naive as to the purposes of the experiment and enrolled in upper division courses at Kent State University, were given course credit for their participation.

\section{Materials}

A questionnaire with several questions concerning the size and motion of objects and sophistication in physics was used.

\section{Design and Procedure}

Only three of the questions presented on the questionnaire will be examined in Experiment 1, and only one was the primary focus of the present study. The participants were first asked, "How long (in feet) is one of the dashed lines on the road that indicate it is okay to pass and separate two lanes of traffic traveling in the same direction on Interstate 76?" Second, they were asked whether they had any previous knowledge of how long the lines actually were (e.g., "Have you ever been employed by the Highway Department?"). No participants were thrown out on the basis of the second question. Third, the participants were asked, "How long (in feet) is one of the spaces between two of the dashed lines on the road that indicate it is okay to pass and separate two lanes of traffic in the same direction on Interstate 76 ?"

\section{Results}

Figure 1 shows the distribution of estimates, from memory, of the length of one of the lines, ranging from 0.05 to $4.57 \mathrm{~m}$. The distribution shows marked skewness in the positive direction, so here we will report the median and the mean. The median estimate of the length of one of the dashed lines on the road was $0.61 \mathrm{~m}(\bar{X}=0.81 \mathrm{~m}$, $S D=0.61 \mathrm{~m}$ ). A one-sample $t$ test indicated that the average estimated length was significantly smaller than the actual length of $4.57 \mathrm{~m}$ in $1994[t(354)=113.05, p<$ $.001]$ and was significantly smaller than the actual length today $(3.05 \mathrm{~m})[t(354)=66.44, p<.001]$. Sixty percent of the observers estimated the length to be $0.61 \mathrm{~m}$ or smaller, $88 \%$ estimated it to be $1.22 \mathrm{~m}$ or smaller, and over

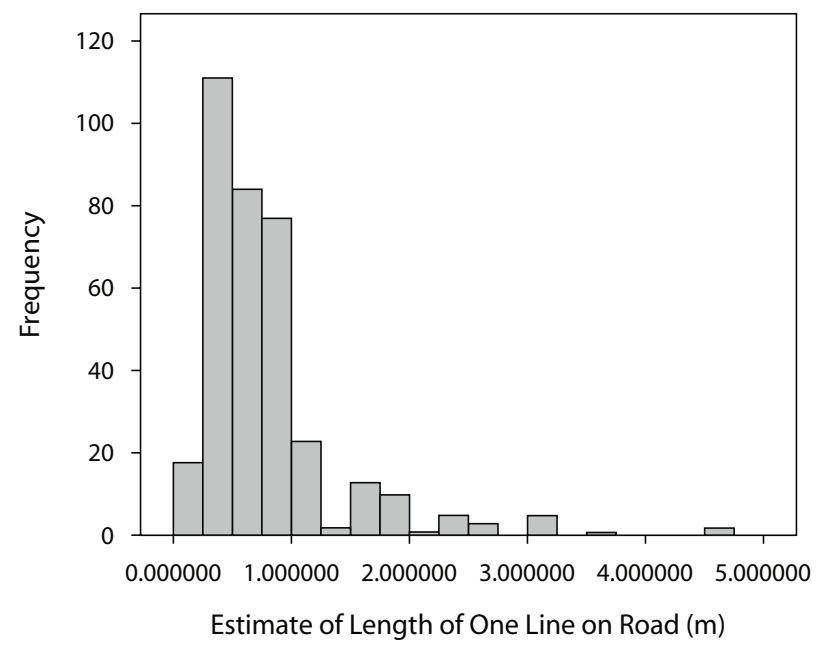

Figure 1. Histogram of observers' estimates, from memory, of the length in meters of one of the lines on the road. 
$95 \%$ of the observers estimated the length to be $1.83 \mathrm{~m}$ or smaller.

The distribution for the spaces between the lines also showed marked skewness, so we again will report both the median and the mean. The median estimate of one of the spaces that separate the dashed lines on the road was also $0.61 \mathrm{~m}(\bar{X}=1.02 \mathrm{~m}, S D=1.44 \mathrm{~m})$. A one-sample $t$ test also indicated that the average estimate was significantly smaller than the actual length $(9.15 \mathrm{~m})[t(354)=106.62$, $p<.001]$.

\section{Discussion}

The participants significantly underestimated the length of the dashed lines on the road. These underestimates were far greater than those previously reported (Harte, 1975) but fit with most people's estimations when one talks with them informally. Out of 355 students, only $2 \%$ estimated the line length to be $3.05 \mathrm{~m}$ or greater. Of equal interest was how compact the distribution was. Spaces between the lines were underestimated as well and were estimated to be as small as the lines on the road. Because the spaces between the lines were twice as long as the lines themselves, the spaces were underestimated by about a factor of two, as compared with the lines. This fits with previous work showing that unfilled space is generally seen as much smaller than filled space (Luria et al., 1967). Estimates of both the lines and the spaces in between the lines are consistent with a dramatic compression (from memory) of 3-D space in the plane parallel to an observer's line of sight.

\section{Possible Explanation of Observers' Underestimations From Memory}

These results may be explained by the observers' converting the visual angle taken up by a line on the road from the perspective of an upright (sitting or standing) observer into physical length, using the average length of these as an estimate of the length of all the lines, and remembering their length that way. In order to determine whether the observers were relying on a conversion of the visual angle of the lines into physical length, the visual angles of all the lines in clear view of an observer looking at the road in front of him or her were calculated from all of the possible perspectives of a driver or passenger in the middle of each of three lanes on a three-lane road (an example of three different visual angles from the perspective of a driver is shown in Figure 2). These were calculated with respect to the same line from three different possible positions on the road. There were 24 total possible perspectives of a passenger or driver (36 total minus 12 perspective views that overlapped between the driver and the passenger and were not counted). The average visual angle of a line on the road from the perspective of a driver or passenger in any three-lane road, converted to physical length, was $0.87 \mathrm{~m}$ (please see note 1 and Figure 3 for all measurements and calculations). ${ }^{1}$ Converted to physical lengths, the visual angles ranged from 0.1 to $1.91 \mathrm{~m}$. A $95 \%$ confidence interval $(t=2.069, \bar{X}=0.87 \mathrm{~m}, S D=1.22 \mathrm{~m})$ indicates that the visual angle of a line on the road that can be seen

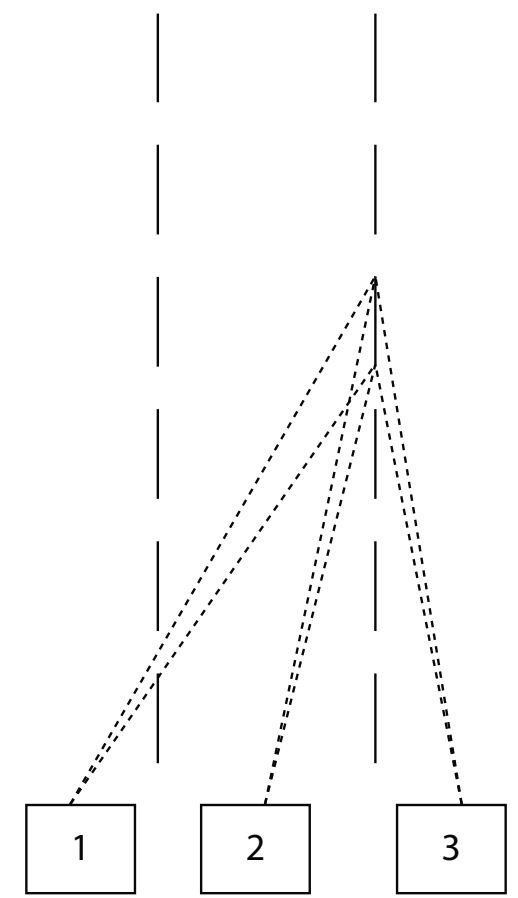

Figure 2. Perspectives of visual angles of the same line on the road from three different positions on a three-lane road.

clearly from any possible position of a passenger or driver, converted to physical length, will be between 0.35 and $1.38 \mathrm{~m}$. Since the confidence interval for the visual angles converted to physical lengths contains the mean estimated length from memory $(0.87 \mathrm{~m})$, it seems that observers may, in general, estimate physical length from the average visual angle of all the lines visible on the road. ${ }^{2}$

\section{EXPERIMENT 2}

The purpose of Experiment 2 was to examine whether the estimations given from memory in Experiment 1 would be different when an independent group of observers was shown a 3.05-m line on the ground from two different distances. The memory estimates in Experiment 1 provide compelling evidence that observers underestimate the length of lines on a road when asked to do so by memory. However, these memorial representations may have been due, at least in part, to memory distortions or an inability to translate size or distance judgments into absolute length estimations. In order to reduce possible estimation biases and remove the possibility that the observers were unable to accurately transform information about object size into an absolute size measurement, we first implemented a magnitude estimation technique that eliminated possible size and distance errors and large individual differences that might arise due to these. We presented the participants in Experiment 2 with one of two viewing conditions. They were shown a $3.05-\mathrm{m}$ line on the ground parallel to their line of sight at either 18.6 or $37.2 \mathrm{~m}$. Compari- 

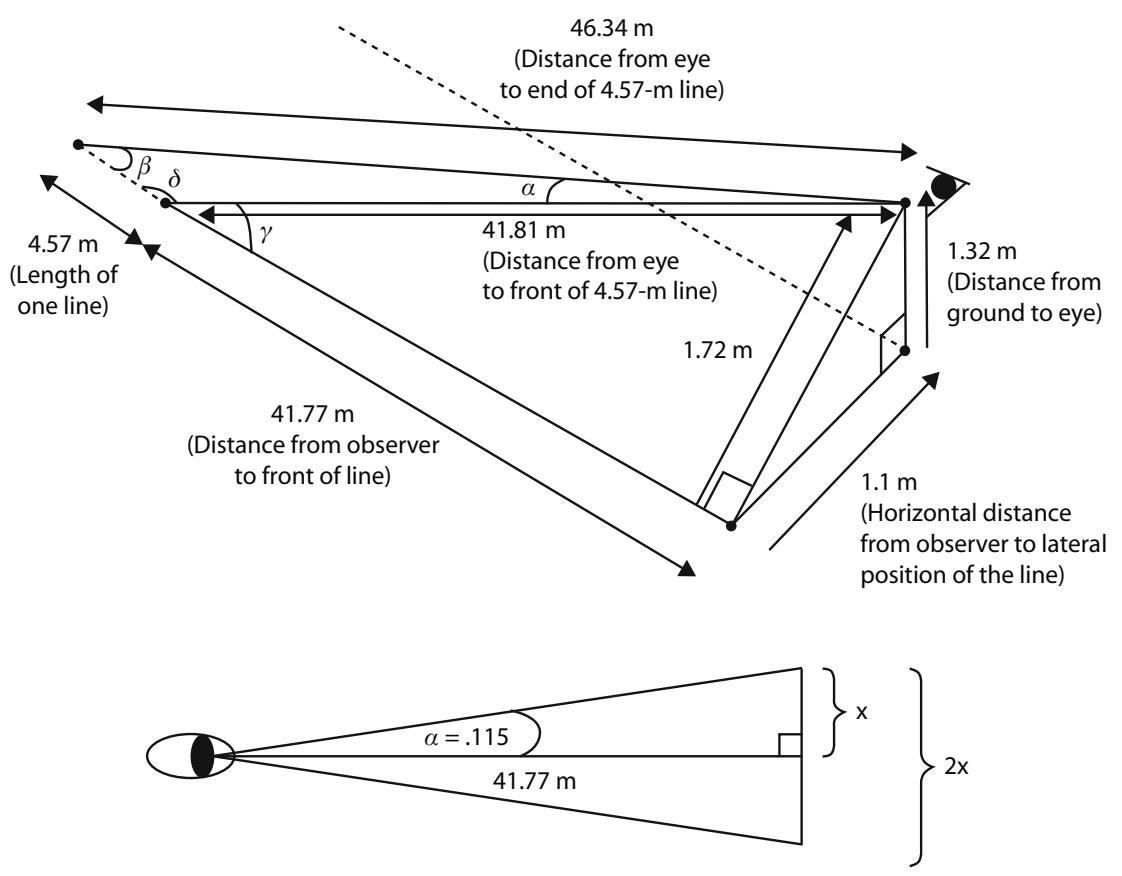

Figure 3. Top: Dimensions for calculating the visual angles formed by lines on the road. Details about distances and angles are given in note 1. Bottom: Setup for converting a visual angle of $0.23^{\circ}$ at $41.77 \mathrm{~m}$ to a physical length perpendicular to the line of sight of the observer.

son lines were presented at the same distance in order to reduce biases that might arise due to adjustment errors (Teghtsoonian, 1972). We then investigated whether both magnitude estimates and verbal estimates in an actual viewing condition would be similar to the estimates given in the memory condition in Experiment 1.

\section{Method}

\section{Participants}

Fifty-one students naive as to the purposes of the experiment, with 20/20 or corrected-to-20/20 vision, and enrolled in two separate introductory psychology courses at the Ohio State University, Mansfield, were given course credit for their participation. Twenty-five students participated in Condition 1, whereas a different group of 31 students participated in Condition 2.

\section{Apparatus}

A 3.05-m long "line" (a piece of construction paper) that was $0.1 \mathrm{~m}$ wide (corresponding to the length and width of dashed lines on the roads in Ohio) was placed at one of two distances (depending on the condition). It was taped to the ground, using transparent tape. It was placed on the ground directly in front of the participants. It looked the way a line on the road would look if one were driving in the car and the line were directly in front of one's car. This was done in order to mimic the appearance of one dashed line on the road. A 0.61-m-long, 0.1-m-wide all-white board was placed upright $0.15 \mathrm{~m}$ to the left of and at the front edge (part of the line closest to the participants) of the $3.05-\mathrm{m}$ line. A 0.61-m-long, 0.1-m-wide line made of the same materials as the $3.05-\mathrm{m}$ line was placed on the ground $0.15 \mathrm{~m}$ to the right of and perpendicular to the front edge of the $3.05-\mathrm{m}$ line on the ground. The $3.05-\mathrm{m}$ line and the $0.61-\mathrm{m}$ line were perpendicular to one another and formed an L-shape on the ground, relative to the observer. We also placed two orange cones $3.05-\mathrm{m}$ apart from one another and $3.05-\mathrm{m}$ from the participants.
The participants used the distance between cones to make estimates of the distance they thought they were from the lines. This was done indoors in the Campus Recreation Center gymnasium on the Ohio State, Mansfield, campus.

\section{Design and Procedure}

Condition 1. The participants stood $37.2 \mathrm{~m}$ from the front edge of the $3.05-\mathrm{m}$ line on the ground. We chose this distance because it represented the distance that the fourth line away from a car would be when being driven down the road (this is typically the first line that is visible [and does not appear blurry] while one is driving on the road). The participants made magnitude estimates of the $0.61-\mathrm{m}$ upright board and 0.61-m perpendicular line, on the basis of a value we assigned to the $3.05-\mathrm{m}$ line. The length of the $3.05-\mathrm{m}$ line was assigned a value of 10 . The participants were told that this value had no units associated with it, such as inches, feet, or meters. It was simply an arbitrary value. The participants were instructed to assign a value to the lengths of the $0.61-\mathrm{m}$ upright board and $0.61-\mathrm{m}$ perpendicular line, on the basis of a value of 10 for the $3.05-\mathrm{m}$ line on the ground. The order of presentation of the board and the perpendicular line estimates was counterbalanced. The participants were then asked to estimate the distance from where they were standing to the front edge of the $0.61-\mathrm{m}$ line on the ground, on the basis of an arbitrary value of 1 for the distance between the two orange cones. The participants were then asked the following three questions: (1) How long do you think the line on the ground oriented away from you actually is? (2) How long do you think the upright board actually is? and (3) How long do you think the line on the ground perpendicular to where you are looking actually is? All the participants answered all the questions. Before making their magnitude estimates of the line lengths, the participants were given practice trials until they clearly understood how to articulate their estimations. All the participants fully understood how to make magnitude estimations with no more than two practice trials. We also asked all the participants after the experiment what the $3.05-\mathrm{m}$ line had looked like to them. All the 
participants reported that it had looked like a flat line on the ground at a great distance from them.

Condition 2. The participants stood $18.6 \mathrm{~m}$ from the front edge of the $3.05-\mathrm{m}$ line on the ground directly in their line of sight. Otherwise, the design and procedure were identical to those in Condition 1 . We chose this distance because we wanted to investigate what would happen to observers' estimates when we showed them a line at half the distance.

\section{Condition 1}

\section{Results}

Just to remind the reader, the participants in Condition 1 stood $37.2 \mathrm{~m}$ away from the lines. The distributions of magnitude estimates for both the upright board and the perpendicular line showed marked skewness. Therefore, we will report the medians as well as the means. The median magnitude estimates for both the upright board and the perpendicular line were $10(\bar{X}=9.52, S D=5.86$, and $\bar{X}=10.51, S D=5.88$, respectively). This indicates that the participants thought that the $3.05-\mathrm{m}$ line was the same length as the $0.61-\mathrm{m}$ upright board and the $0.61-\mathrm{m}$ line on the ground. Two separate one-sample $t$ tests revealed no difference between the arbitrary value of 10 assigned to the $3.05-\mathrm{m}$ line on the ground and the participants' magnitude estimates of the length of the board or the perpendicular line $[t(24)=0.24, p>.5$, and $t(24)=0.43$, $p>.5$, respectively].

The distributions for verbal estimates of how long the lines and board were also showed marked skewness, so we again will report both the medians and the means. The median estimate for the $3.05-\mathrm{m}$ line on the ground was $0.92 \mathrm{~m}(\bar{X}=1.41, S D=1.13 \mathrm{~m})$. This was a significant underestimation of the actual length $[t(24)=7.25$, $p<.001]$. The median estimate for the upright board was $0.76 \mathrm{~m}(\bar{X}=0.85 \mathrm{~m}, S D=0.51 \mathrm{~m})$. This was significantly different from the actual length $[t(24)=2.33, p<$ $.05]$. The median estimate for the $0.61-\mathrm{m}$ perpendicular line on the ground was $0.61 \mathrm{~m}(\bar{X}=0.68 \mathrm{~m}, S D=0.38)$. This was not significantly different from its actual length $[t(24)=0.89, p>.3]$. The top panel of Figure 4 shows the observers' verbal estimates (in meters) of how long they thought the lines actually were. The mean verbal estimates and the corresponding standard errors for both conditions are shown versus the actual length of the line. The bottom panel shows the mean converted visual angles and the corresponding standard errors for both conditions (Condition $1=37.2 \mathrm{~m}$ ) versus the actual visual angle of the $3.05-\mathrm{m}$ line in both conditions.

The distance estimates from the lines also showed marked skewness. The median magnitude estimate of the distance from the lines was $12(\bar{X}=15.52, S D=5.88)$. This was not significantly different from actual (12.2) $[t(24)=1.43, p>.1]$.

\section{Condition 2}

To again remind the reader, the participants in Condition 2 stood $18.6 \mathrm{~m}$ away, or at half the distance the participants in Condition 1 stood away from the lines. The distributions for the magnitude estimates for both the upright board and the perpendicular line showed marked skewness, so we will report the medians as well as the
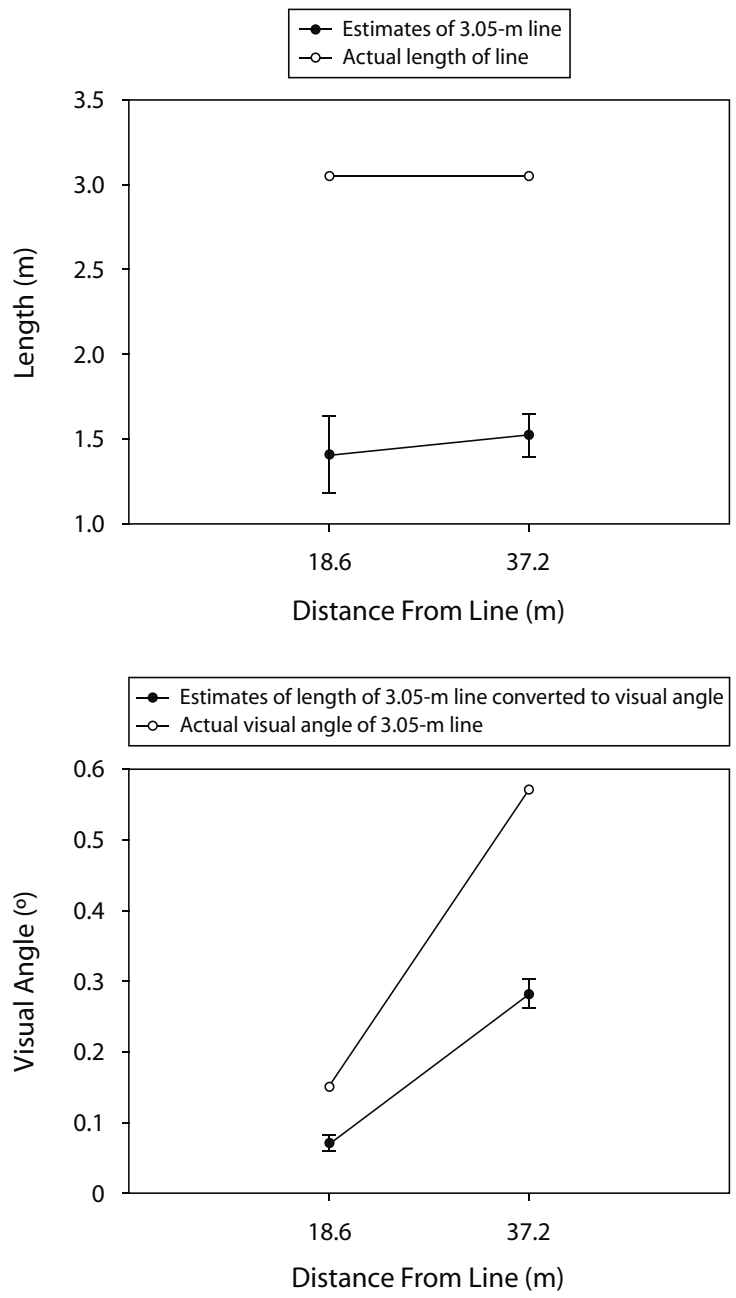

Figure 4. Top: Observers' verbal estimates (in meters) of how long they thought the line actually was. The mean verbal estimates and the corresponding standard errors for estimations from 18.6 and $37.2 \mathrm{~m}$ are shown versus the actual length of the line $(3.05 \mathrm{~m})$. Bottom: Mean converted visual angles and the corresponding standard errors for estimations from 18.6 and $37.2 \mathrm{~m}$ versus the actual visual angle of the 3.05-m line from 18.6 and $37.2 \mathrm{~m}$.

means. The median magnitude estimate for both the upright board and the perpendicular line was $5(\bar{X}=5.55$, $S D=1.65$ and $\bar{X}=6.03, S D=3.13$, respectively). This indicates that the participants thought that the $3.05-\mathrm{m}$ line was twice the length of the 0.61 -m upright board and perpendicular line. It also suggests that there is an invariance of the projection angle (at least as given by magnitude estimation), since the estimates by different participants were twice as large at half the distance.

The distributions for verbal estimates of how long the lines and board actually were also showed marked skewness, so we again will report both the medians and the means. The median estimate of the 3.05-m line on the ground was $1.52 \mathrm{~m}(\bar{X}=1.52 \mathrm{~m}, S D=0.72 \mathrm{~m})$. This was still a significant underestimation of the actual length 
$[t(30)=11.82, p<.001]$. The median estimate of the upright board was $0.76 \mathrm{~m}(\bar{X}=0.74 \mathrm{~m}, S D=0.27 \mathrm{~m})$. This was significantly different from its actual length $[t(30)=$ $2.61, p=.01]$. The median estimate of the $0.61-\mathrm{m}$ perpendicular line on the ground was $0.61 \mathrm{~m}(\bar{X}=0.71 \mathrm{~m}$, $S D=0.27 \mathrm{~m}$ ). This was not significantly different from its actual length $[t(30)=1.97, p=.06]$. The top panel of Figure 4 shows the observers' verbal estimates (in meters) of how long they thought the lines actually were. The mean verbal estimates and the corresponding standard errors for both conditions are shown versus the actual length of the line. The bottom panel shows the mean converted visual angles and the corresponding standard errors for both conditions (Condition $2=18.6 \mathrm{~m}$ ) versus the actual visual angle of the $3.05-\mathrm{m}$ line in both conditions.

The estimates of distance from the lines also showed marked skewness. The median magnitude estimate of the distance from the lines was $4(\bar{X}=6.76, S D=9.1)$. This was not significantly different from the actual distance (6.1) $[t(30)=0.40, p>.6]$.

\section{Discussion}

Experiment 2 showed that when possible distortions due to memory were controlled by presenting the lines to observers in a live viewing condition and by using magnitude estimation, participants estimated the length of a line on the ground $(3.05 \mathrm{~m})$ to be the same as that of a $0.61-\mathrm{m}$ upright board and a $0.61-\mathrm{m}$ perpendicular line on the ground from $37.2 \mathrm{~m}$ away, and to be about twice that length at one half the distance. Their estimations of length in the frontoparallel plane (of the 0.61-m upright board) and their distance estimations were reasonably accurate in both conditions, indicating that the reduced size they gave to the line on the ground was not due to a foreshortening of all lengths at a given distance or to their inaccurate estimations of distance to the object. In fact, there was a slight overconstancy of the $0.61-\mathrm{m}$ upright board in both conditions. This result of overconstancy of vertical objects in depth has been reported in previous studies (Higashiyama, 1992; Higashiyama \& Kitano, 1991). The reasonably accurate distance estimates are consistent with a pattern of results found in the literature, that although information in the environment is often not used to its fullest potential to estimate distance, observers are able to take advantage of much of the information to estimate distances across homogeneous surfaces reasonably accurately, and this can also be taken into account to perceive the extent of objects (Foley et al., 2004; Meng \& Sedgwick, 2002; Ooi, Wu, \& He, 2001; Sinai, Ooi, \& He, 1998; Wu, Ooi, \& He, 2004).

The magnitude estimates of the $3.05-\mathrm{m}$ line on the ground from $37.2 \mathrm{~m}$ were equivalent to those of a $0.61-\mathrm{m}$ upright board, indicating that the participants perceived the line to be about $0.61 \mathrm{~m}$ long. The visual angle of the $3.05-\mathrm{m}$ line, converted to physical length on the ground at $37.2 \mathrm{~m}$, was equivalent to $0.1 \mathrm{~m}$, and that of the $3.05-\mathrm{m}$ line at $18.6 \mathrm{~m}$ was equivalent to $0.19 \mathrm{~m}$. Thus, the observers' magnitude estimates, converted to physical lengths of $0.89 \mathrm{~m}$ and $1.33 \mathrm{~m},{ }^{3}$ were from seven to nine times longer than the actual visual angles, converted to physical lengths. In addition, although the verbal estimates given in both conditions in Experiment 2 (0.92 and $1.52 \mathrm{~m}$ ) fell within the $95 \%$ confidence interval that described the visual angles of all of the lines on the road, converted to physical lengths $(0-1.55 \mathrm{~m})$ (see Figure 2 and note 1 ), they were also eight to nine times larger than the actual visual angle. Thus, the observers did not seem to use the visual angle exactly to estimate the physical size of one of the lines when looking at it. This is consistent with work that shows that observers do not process visual angles precisely and tend to enlarge smaller visual angles (Higashiyama, 1992). Much work has also shown that past history and significance, familiar size, and other cognitive processes may "add to" the visual angle or our phenomenal impressions of object size, in order to increase object size toward the actual size (Foley et al., 2004; Gilinsky, 1951; Gogel, 1974, 1998; Gogel \& Da Silva, 1987; Higashiyama \& Kitano, 1991; Matsushima et al., 2005; Thouless, 1931). Although verbal estimates were far longer than the visual angle predictions, it seems that the observers were utilizing some characteristics of visual angle, because the estimates of length doubled with a halving of the distance to the lines. This is consistent with work showing that the anisotropy of perceived 3-D object length is invariant across proportionate increases to distance and the visual angle and occurs even under full viewing conditions (Loomis \& Philbeck, 1999; Norman et al., 1996; Todd et al., 1995).

The third focus of this study, presented in the introduction, was to test whether our results fit with the tangle model proposed by Foley et al. (2004) (assuming that our results were non-Euclidean, as they were in Experiment 2). The transformed angle or tangle model proposed by Foley et al. makes visual extents more similar to physical extents. One appealing characteristic of the model that, at first glance, seems to fit our data is that the model is visual angle dependent and the visual angle itself is substituted with an increasing function of the visual angle. The tangle model holds perceived size and distance invariant for the same visual angle and varies perceived size with both orientation in the horizontal plane and visual angle (specific details may be found in Foley et al., 2004). Due to the fact that we did not ask our observers to estimate distance to the end of the line, we have to assume the values of the parameters of the perceived egocentric distance function used in the tangle model. They are $F=1.25$ and $G=0.007$ (from Foley et al.'s [2004] Equation 5 [p. 149]). We have also used Foley et al.'s values of $P$ and $Q$ to compute the effective angle of the lines $(P=0.57, Q=0.31)$ using Equation 3 (p. 148). The tangle model provided an excellent fit to our data, accounting for over $99 \%$ of the variance in verbal estimates of extent from $18.6 \mathrm{~m}$ away $(r=.998, p<.001)$ and from $37.2 \mathrm{~m}$ away $(r=.997, p<$ $.001)$. Figure 5 shows the relationship between predicted extent by the tangle model and reported extent (observers' verbal estimates) from both $18.6 \mathrm{~m}$ and $37.2 \mathrm{~m}$.

\section{EXPERIMENT 3}

We sought to test whether our findings from the laboratory would translate to the situation in which observers 


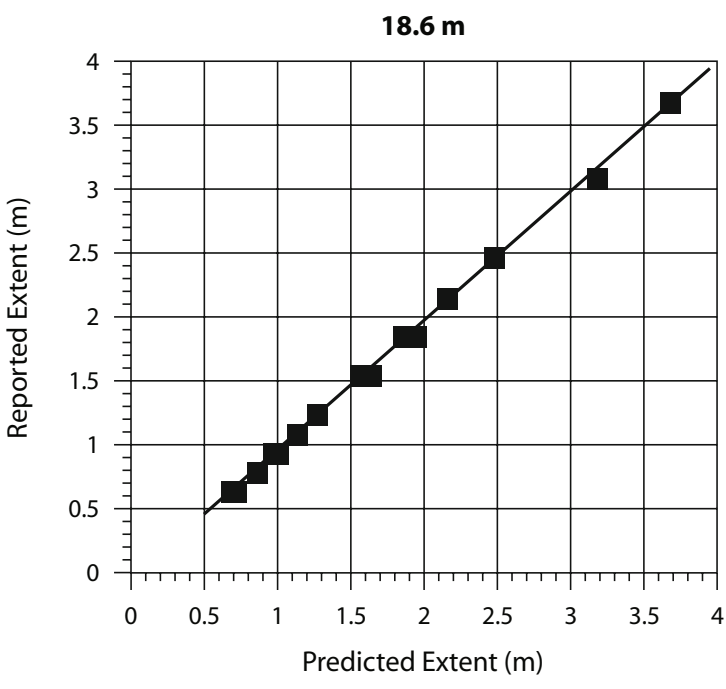

$37.2 \mathrm{~m}$

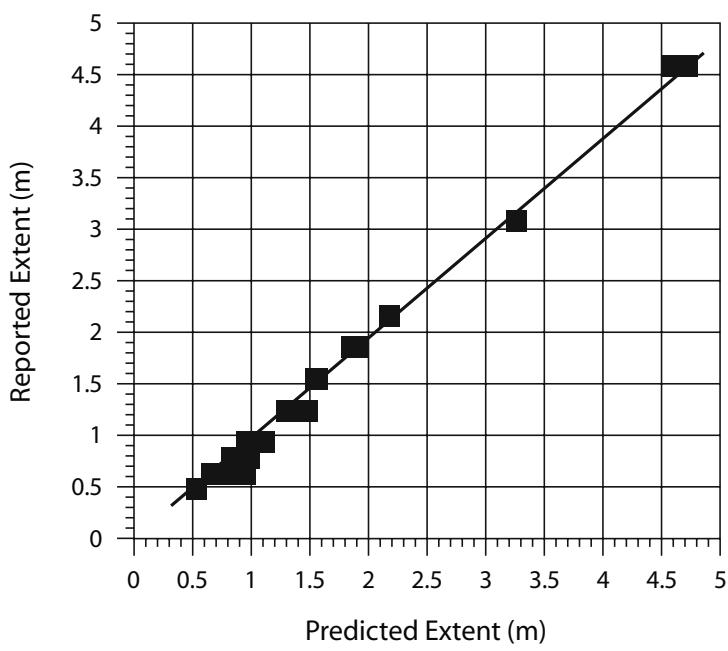

Figure 5. Reported extent (verbal estimates from Experiment 2) versus predicted extent by the tangle model for distances of $\mathbf{1 8 . 6}$ and $37.2 \mathrm{~m}$. We have used the values of the parameters of the perceived egocentric distance function $(F=1.25$ and $G=0.007$ from Foley, Ribeiro-Filho, and Da Silva's [2004] Equation 5) and the values of $P$ and $Q$ to compute the effective angle of the lines $(P=0.57, Q=0.31)$, using Foley et al.'s Equation 3 .

were placed in a car traveling on the road. Thus, Experiment 3 examined whether the findings of Experiment 2 would generalize to the condition in which people probably first and most commonly encounter the lines on the road.

\section{Method}

\section{Participants}

Twenty-eight introductory psychology students at Kent State University, naive as to the previous experiments, with $20 / 20$ or correctedto-20/20 vision, received course credit for their voluntary participation.

\section{Design and Procedure}

The participants were blindfolded and seated in the front or back seat of a 1994 Chevrolet Geo Prism. Participants were randomly assigned to three conditions. The first was their sitting position in the car. Fourteen participants sat in the passenger-side back seat, and 14 participants sat in the passenger-side front seat. The second condition was the speed at which the car was traveling. The participants reported estimations when the car reached and was maintained at either 40.25 or $96.6 \mathrm{~km} / \mathrm{h}$. Fifteen participants gave estimates when the car was traveling at $40.25 \mathrm{~km} / \mathrm{h}$, and 13 gave estimates when the car was traveling at $96.6 \mathrm{~km} / \mathrm{h}$. In the third condition, we varied where the participants looked at the lines. After taking the blindfold off, we told the participants to look at the lines closest to the front and back of the car. All the participants reported estimates from the front and back. The order in which the participants were told to look at the lines (front and back) was counterbalanced. The first two conditions were performed to test whether the participants' estimates depended on the position in the car from which they were looking at the lines or on the speed at which the car was traveling. Because the results of the previous experiments point to the fact that observers seem to use either the visual angle or an increasing function of the visual angle of the line to make their estimates, it was expected that these two factors would have no impact on their estimates, due to the fact that, in both these conditions, the visual angle remained unchanged.

\section{Results}

The mean estimates were 1.18 and $1.2 \mathrm{~m}$, when the participants were looking out the front and back of the car, respectively. A 2 (where participants were looking) $\times 2$ (seating position) $\times 2$ (speed at which the car was traveling) mixed-factors ANOVA was performed on the data. There were no significant main effects for speed of the car or where seated in the car $[F(1,24)=1.52$ and 0.93 , respectively; both $p \mathrm{~s}>$.1]. The factor of where the participants were looking at the lines (the front or back of the car) was also not statistically significant $(p>.5)$. The mean for lines estimated in the car (putting back and front estimates together $=1.19 \mathrm{~m}$ ) was not statistically different from the visual angle of the line in front of the car, converted to physical length $(\bar{X}=1.11 \mathrm{~m})[t(55)=0.64$, $p>.5$ ). In addition, two one-sample $t$ tests using a Bonferroni correction showed that each set of estimates was significantly smaller than the actual length of the lines $[t(27)=16.04$ (front), and 28.7 (back), both $p$ s $<.001]$.

\section{Discussion}

Estimates of the lines on the road when the participants traveled in a car were no different from the visual angle converted to physical length and were also significantly smaller than the lines on the road, consistent with Experiments 1 and 2. The estimates in the present experiment were based on lines that were very close to the participants, but they were still large underestimates of the actual length of the lines. The reason for this is that no matter how close one is to the line while in one's car, the line's orientation, relative to one, creates a very small visual angle. For instance, for the largest visual angle of a line on the road shown in Figure 2 (Position 1, line closest to all the positions and farthest to the right), the visual angle, converted to physical length, is only $1.66 \mathrm{~m}$. This length becomes even smaller if one considers only one set of dashed lines 
on the road, as occurs on many roads (including the ones used in the present experiment).

\section{GENERAL DISCUSSION}

Observers showed a great underestimation of the length of lines on the road whether recalling their size from memory, actually viewing them while standing in front of them at varying distances, or riding in a car traveling on the road. These results generally fit with previous findings that have shown how visual space is distorted in an affine manner, so that perceived intervals in depth appear to become systematically compressed with depth, relative to perceived intervals in the horizontal or vertical direction (Beusmans, 1998; Foley et al., 2004; Gilinsky, 1951; Gogel, 1964; Haber, 1985; Harway, 1963; Hecht et al., 1999; Kudoh, 2005; Loomis et al., 1992; Loomis \& Philbeck, 1999; Matsushima et al., 2005; Norman et al., 2005; Norman et al., 1996; Todd \& Norman, 2003; Todd et al., 1995; Toye, 1986; Wagner, 1985).

Two differences separate the present work from earlier work. First, the perceived compression shown in three out of four conditions (and five out of six sets of estimates) in the present work is far greater than that found in previous work. In Experiment 1, there was $\sim 87 \%$ compression of the size of the lines. The magnitude estimates in Experiment 2 showed $\sim 80 \%$ compression, whereas the verbal estimates showed $\sim 70 \%$ and $50 \%$ compression (Conditions 1 and 2 , respectively). The verbal estimates in Experiment 3 showed $\sim 75 \%$ compression. Most previous work shows $\sim 15 \%-$ $50 \%$ compression of depth intervals when estimates are made 4-40 m away (Foley et al., 2004; Haber, 1985; Harway, 1963; Hecht et al., 1999; Kudoh, 2005; Loomis et al., 1992; Loomis \& Philbeck, 1999; Matsushima et al., 2005; Norman et al., 2005; Toye, 1986; Wagner, 1985). Even for closer lengths, perceived intervals become systematically compressed with depth, whereas perceived intervals in the frontoparallel plane increase slightly or remain relatively constant (Norman et al., 1996; Todd \& Norman, 2003). In Condition 2 of Experiment 2, the compression ( $50 \%)$ was comparable to that in other studies. In this condition, however, we basically told the participants that they were underestimating using magnitude estimation, asking them, "How long do you think the line actually is?" So why was there greater compression in the present study? One possibility is that in previous work, researchers asked their participants to estimate distances between two objects, and not the length of one object positioned directly in front of the observer. Many times, these objects (typically, poles) were offset from one another, so that one was not directly behind the other. Even if the poles were outside the range of operable 3-D depth cues, as some of them were, there would be more information to use about distance than there would be if they were directly in line with each other and the observer. Thus, the estimates we found here may be an extreme case for the anisotropy of perceived 3-D object length.

A second difference of the present work, as compared with previous work, that may also explain the compression differences is that (at least in Experiments 1 and 3) the object was familiar, even though its physical length was not. ${ }^{4}$ Typically, when the size of an object is familiar, size-distance scaling allows the observer to perceive the object as the same size, despite changes in the retinal image. However, in this case, the observers were not familiar with the physical size. Some evidence suggests that there is a mechanism in place to maintain constancy of the apparent, or assumed, size of an object (Wootton, Sharp, \& Granrud, 2004). Participants who were shown one size of a stoplight in a familiarization trial estimated the size of different-sized stoplights according to the one in the familiarization trial. This work demonstrated that size constancy for distant objects relies on what observers assume the size of the object is and is not so much a feature of perception or of the physical size of the object (Wootton et al., 2004). This would help to explain why the observers' estimates were so similar across a broad range of conditions and why the observers gave estimates in Experiments 1 and 3 similar to those in Experiment 2, despite the fact that the physical line length changed from 4.57 to $3.05 \mathrm{~m}$. This would also help to explain the observers' similar estimates of the line lengths across conditions in which they had opportunities to cognitively correct for the actual length when they were asked an open-ended question about how long they thought the lengths were (Experiment 1), as compared with conditions in which they were not allowed to cognitively correct for their perceptions (e.g., the magnitude estimates given in Experiment 2).

The present work also extends the work of Foley et al. (2004) by showing that the tangle model predicts very well the results we found in Experiment 2. Although the tangle model accounts for a lot of the perceived extent data in a variety of contexts, Foley et al. were unsure how the tangle model would apply in cases in which cognitive factors, such as beliefs about the extents of objects, determine the results. The data we used in Experiment 2 were from a question we asked the participants after they had made their magnitude estimates: "How long do you think the line actually is?" In debriefing the participants, many indicated that when we asked them this, they knew that it could not be as small as it looked, so they gave a correction. Thus, it seems that we essentially told them its length was not as short as they perceived it to be. Even with the cognitive corrections that they made to their original magnitude estimates, the tangle model predicted our results extremely well. This extends the generality of the tangle model to conditions in which cognitive factors may play a large role.

The underestimation of the length of lines on a road shown in the present work can presumably be linked to other objects whose sizes are unfamiliar to observers and are outside the range in which traditional size constancy scaling mechanisms are most effective. This work has implications for judging the size of objects tilted away from observers, both lying on the ground and high in the air (Loomis, Philbeck, \& Zahorik, 2002; Pizlo, 1994; Thouless, 1931; Van de Geer \& Zwaan, 1966). Kaiser (1967) showed that trapezoids were perceived as smaller and smaller when placed at $15^{\circ}, 45^{\circ}$, and $65^{\circ}$, with the tops receding away from the frontoparallel plane. Similarly, Loomis and Philbeck (1999) found that perceptual shape distortion is 
dependent on the optical slant of the 2-D retinal image being judged. The same interpretations have been found for cases in which objects have been looked down at from above (Gogel, 1998; Gogel \& Eby, 1997; Ohba, 1966). Research has also shown that for objects high up in their field of view, observers make similar underestimations. For instance, McBeath, Neuhoff, and Schiano (1993) and Granrud, Granrud, Koc, Peterson, and Wright (2003) found that observers estimated the diameter of one of the lenses in a traffic light to be approximately $20.3 \mathrm{~cm}$, when in fact it was $30.5 \mathrm{~cm}$ (i.e., traffic lights at major intersections; see also Wootton et al., 2004). Future work will address the issue of how lines are perceived as they are placed at systematically greater angles from the frontoparallel plane and whether the extent of underestimations found here for lines can also be observed with other objects.

\section{AUTHOR NOTE}

We thank the Department of Public Safety at Arizona State University West for allowing us to use the Chevy Caprice to make the calculations given in note 1. We also thank Thomas Gregory, Del Lindsey, Heiko Hecht, and Jeffrey Anastasi for helpful comments regarding the manuscript. Correspondence concerning this article should be addressed to D. M. Shaffer, Department of Psychology, Ohio State University, 1680 University Drive, Mansfield, OH 44906 (e-mail: shaffer.247@osu.edu).

Note-Accepted by the editorial board of Editor-Elect Jeremy M. Wolfe.

\section{REFERENCES}

Battro, A. M., Netto, S. P., \& Rozestraten, R. J. A. (1976). Riemannian geometries of variable curvature in visual space: Visual alleys, horopters, and triangles in big open fields. Perception, 5, 9-23.

Beusmans, J. M. H. (1998). Optic flow and the metric of the visual ground plane. Vision Research, 38, 1153-1170.

BLANK, A. A. (1958). Analysis of experiments in binocular space perception. Journal of the Optical Society of America, 48, 911-925.

Foley, J. M., Ribeiro-Filho, N. P., \& Da Silva, J. A. (2004). Visual perception of extent and the geometry of visual space. Vision Research, 44, 147-156.

GiLInSKY, A. S. (1951). Perceived size and distance in visual space. Psychological Review, 58, 460-482.

GogeL, W. C. (1964). Visual perception of spatial extent. Journal of the Optical Society of America, 54, 411-416.

Gogel, W. C. (1974). Cognitive factors in spatial responses. Psychologia, 17, 213-225.

GoGEL, W. C. (1998). An analysis of perceptions from changes in optical size. Perception \& Psychophysics, 60, 805-820.

Gogel, W. C., \& DA Silva, J. A. (1987). Familiar size and the theory of off-sized perceptions. Perception \& Psychophysics, 41, 318-328.

Gogel, W. C., \& Eвy, D. W. (1997). Measures of perceived linear size, sagittal motion, and visual angle from expansions and contractions. Perception \& Psychophysics, 59, 783-806.

Granrud, C. E., Granrud, M. A., Koc, J. C., Peterson, R. W., \& Wright, S. M. (2003). Perceived size of traffic lights: A failure of size constancy for objects viewed at a distance. Journal of Vision, 3, 491a. Available at journalofvision.org/3/9/491, doi: 10.1167/3.9.491.

HABER, R. N. (1985). Toward a theory of the perceived spatial layout of scenes. Computer Vision, Graphics, \& Image Processing, 31, 282-321.

HaRTE, D. B. (1975). Estimates of the length of highway guidelines and spaces. Human Factors, 17, 455-460.

HARWAY, N. I. (1963). Judgment of distance in children and adults. Journal of Experimental Psychology, 65, 385-390.

Hecht, H., van Doorn, A., \& Koenderink, J. J. (1999). Compression of visual space in natural scenes and in their photographic counterparts. Perception \& Psychophysics, 61,1269-1286.

HigashiYAMA, A. (1992). Anisotropic perception of visual angle: Impli- cations for the horizontal-vertical illusion, overconstancy of size, and the moon illusion. Perception \& Psychophysics, 51, 218-230.

Higashiyama, A., \& Kitano, S. (1991). Perceived size and distance of persons in natural outdoor settings: The effects of familiar size. Psychologia, 34, 188-199.

KaISER, P. K. (1967). Perceived shape and its dependency on perceived slant. Journal of Experimental Psychology, 75, 345-353.

KoenderinK, J. J., van Doorn, A. J., \& Lappin, J. S. (2000). Direct measurement of the curvature of visual space. Perception, 29, 69-79.

KuDOH, N. (2005). Dissociation between visual perception of allocentric distance and visually directed walking of its extent. Perception, 34,1399-1416.

Loomis, J. M., Da Silva, J. A., Fujita, N., \& Fukusima, S. S. (1992). Visual space perception and visually directed action. Journal of Experimental Psychology: Human Perception \& Performance, 18 , 906-921.

LoOMIS, J. M., \& PHILBecK, J. W. (1999). Is the anisotropy of perceived 3-D shape invariant across scale? Perception \& Psychophysics, 61, 397-402.

Loomis, J. M., Philbeck, J. W., \& Zahorik, P. (2002). Dissociation between location and shape in visual space. Journal of Experimental Psychology: Human Perception \& Performance, 28, 1202-1212.

LUNEBURG, R. K. (1950). The metric of binocular visual space. Journal of the Optical Society of America, 40, 627-642.

LuRIA, S. M., KinNey, J. S., \& WeIsSman, S. (1967). Distance estimates with "filled" and "unfilled" space. Perceptual \& Motor Skills, 24, $1007-1010$

Matsushima, E. H., De Oliveira, A. P., Ribeiro-Filho, N. P., \& Da Silva, J. A. (2005). Visual angle as determinant factor for relative distance perception. Psicológica, 26, 97-104.

McBeath, M. K., Neuhoff, J. G., \& Schiano, D. J. (1993, June). Familiar suspended objects appear smaller than actual independent of viewing distance. Poster presented at the 5th Annual Meeting of the American Psychological Society, Chicago.

Meng, J. C., \& Sedgwick, H. A. (2002). Distance perception across spatial discontinuities. Perception \& Psychophysics, 64, 1-14.

Norman, J. F., Crabtree, C. E., Clayton, A. M., \& Norman, H. F. (2005). The perception of distances and spatial relationships in natural outdoor environments. Perception, 34, 1315-1324.

Norman, J. F., Todd, J. T., Perotti, V. J., \& Tittle, J. S. (1996). The visual perception of three-dimensional length. Journal of Experimental Psychology: Human Perception \& Performance, 22, 173-186.

Онва, S. (1966). Changes of perceived size of object in the downward viewing condition to the ground. Psychologia, 9, 95-101.

Ohio Department of Transportation (2005). Ohio manual of uniform traffic control devices. Columbus, $\mathrm{OH}$ : Author.

OoI, T. L.,Wu, B., \& HE, Z. J. (2001). Distance determined by the angular declination below the horizon. Nature, 414, 197-200.

PizLo, Z. (1994). A theory of shape constancy based on perspective invariants. Vision Research, 34, 1637-1658.

SinaI, M. J., OoI, T. L., \& He, Z. J. (1998). Terrain influences accurate judgment of distance. Nature, 395, 497-500.

Teghtsoonian, M. (1972). Apparent length as a function of tilt does not depend on orientation of the standard. Journal of Experimental Psychology, 94, 191-197.

Thouless, R. H. (1931). Phenomenal regression to the real object: I. Journal of Psychology, 21, 339-359.

TodD, J. T., \& Norman, J. F. (2003). The visual perception of 3-D shape from multiple cues: Are observers capable of perceiving metric structure? Perception \& Psychophysics, 65, 31-47.

Todd, J. T., TitTle, J. S., \& Norman, J. F. (1995). Distortions of threedimensional space in the perceptual analysis of motion and stereo. Perception, 24, 75-86.

ToYE, R. C. (1986). The effect of viewing position on the perceived layout of space. Perception \& Psychophysics, 40, 85-92.

VAN DE Geer, J. P., \& ZwaAn, E. J. (1966). Size-constancy as dependent upon the angle of regard and spatial direction of the stimulus object. American Journal of Psychology, 77, 563-575.

Wagner, M. (1985). The metric of visual space. Perception \& Psychophysics, 38, 483-495.

Wootton, K. I., Sharp, J. L., \& Granrud, C. E. (2004). Perceived size of traffic stoplights: Effects of assumed size on observers' size 
estimates. Journal of Vision, 4, 885a. Available at journalofvision .org/4/8/885, doi: 10.1167/4.8.885.

Wu, B., OoI, T. L., \& He, Z. J. (2004). Perceiving distance accurately by a directional process of integrating ground information. Nature, 428, 73-77.

\section{NOTES}

1. The visual angles from all possible perspectives of a driver or passenger on a three-lane road were calculated using the following dimensions: (1) those from a Chevy Caprice Phoenix police cruiser; (2) the lengths of the lines $=4.57 \mathrm{~m}$, and the spaces between the lines $=9.15 \mathrm{~m}$; (3) the average width of 31 traffic lanes measured on 15 different roads $(3.32 \mathrm{~m})$, the average distance from the eyes of the driver to the line (in the left lane looking at a line closest to the right $=2.22 \mathrm{~m}$; in the right lane looking at the line closest to the left $=1.1 \mathrm{~m}$ ), and the distance of $5.18 \mathrm{~m}$ to the line closest to the driver (including the size of the hood of the car and the distance the line must be in front of the car for it to be visible). Figure 3 (top) shows the dimensions and angles used in calculating the visual angles. One can calculate angle $\gamma$ using the formula:

$$
\sin ^{-1} \gamma=\frac{1.72 \mathrm{~m}}{41.81 \mathrm{~m}} \approx 2.36^{\circ} .
$$

The line extending from the observer's eye to the front of the line creates two supplementary angles: $\gamma=2.36^{\circ}$ and $\delta=177.64^{\circ}\left(180^{\circ}-2.36^{\circ}\right)$. One can then find angle $\beta$ using the formula:

$$
\sin ^{-1} \beta=\frac{1.72 \mathrm{~m}}{46.34 \mathrm{~m}} \approx 2.13^{\circ} .
$$

The visual angle $\alpha$ is found by adding the two angles already calculated $\left(177.64^{\circ}+2.13^{\circ}\right)=179.77^{\circ}$ and subtracting from $180^{\circ}$ to get $\alpha \approx 0.23^{\circ}$.

The tangent function can then be used to calculate the physical length of a line at a distance that is equal to a visual angle $=0.23^{\circ}$ :

$$
\tan \left(\frac{\alpha}{2}\right)=\frac{X}{41.77 \mathrm{~m}}=\tan \left(0.115^{\circ}\right)=\frac{X}{41.77 \mathrm{~m}} .
$$

Figure 3 (bottom) shows the setup for converting a visual angle of $0.23^{\circ}$ at $41.77 \mathrm{~m}$ to a physical length perpendicular to the line of sight of the observer. After the appropriate algebraic manipulations are performed, the physical length that corresponds to a visual angle of $0.23^{\circ}$ is equal to $\sim 0.17 \mathrm{~m}$ for that one position.

We chose to use a Chevy Caprice police cruiser as the vehicle from which to make our measurements because a medium-sized car seems to be a more "typical" type of car (although this might be questionable, given the number of pickup trucks and sport utility vehicles [SUVs] on the road today). However, the difference between the visual angle converted to physical length for the car we chose, a pickup truck, and an SUV is very minimal. The reason for this is that although one sits at a higher level in a truck or SUV (for instance, $1.6 \mathrm{~m}$ in the Dodge Ram 2500 pickup truck vs. $1.32 \mathrm{~m}$ in the Chevy Caprice police cruiser), this is offset by the fact that in the police cruiser, the first line is visible from $5.18 \mathrm{~m}$ away, whereas this distance becomes $8.2 \mathrm{~m}$ in the Dodge Ram, because the hood is longer. Thus, although we acknowledge that there are differences in visual angle sizes of the lines among vehicles, these differences are very minimal and fall within the range of the confidence interval obtained via the calculations above (e.g., when all the possible visual angles from the perspective of the Dodge Ram are calculated, they fall within this range).

2. Currently, as was stated in the introduction, Ohio roads have $3.05-\mathrm{m}$ lines and 7.62-m spaces in between $(\bar{X}=0.65 \mathrm{~m}, S D=0.81 \mathrm{~m}, 95 \% \mathrm{CI}$ : $\{0.31 \mathrm{~m}, 0.99 \mathrm{~m}\})$.

3. We calculated the converted equivalent median magnitude estimation lengths using the ratio of mean magnitude estimate/mean estimate (m) given to the $0.61-\mathrm{m}$ upright board $=$ arbitrary value given to the $(3.05 \mathrm{~m})(10) / X$ (equivalent physical length). We then solved for the equivalent physical length for the $3.05-\mathrm{m}$ line at 37.2 and $18.6 \mathrm{~m}$ :

and

$$
37.2 \mathrm{~m}: \frac{9.52}{0.85 \mathrm{~m}}=\frac{10}{X} ; \quad X=0.89 \mathrm{~m}
$$

$$
18.6 \mathrm{~m}: \frac{5.55}{0.74 \mathrm{~m}}=\frac{10}{X} ; \quad X=1.33 \mathrm{~m} .
$$

4. One caveat is in order here. The lines on the road do not have the 3-D shape associated with most objects. They are typically created using paints or thermoplastics on the pavement (occasionally, they appear as raised pavement markings). This might create differences between the results found here and what one might find with objects having 3-D shape. However, we tried laying several objects on the ground at $100 \mathrm{ft}$ away (the authors included), and the impression was that all the objects shrunk in length (including ourselves). This was the case with the added cue of familiarity of the approximate physical sizes of the objects. Thus, although one must proceed carefully in generalizing from the lines on the road to other objects, it appears that there is a relevant connection.

(Manuscript received December 23, 2007; revision accepted for publication June 24, 2008.) 